\title{
ADAPTASI DAN PERENCANAAN PRODUKSI ALAT PELINDUNG DIRI PADA MASA PANDEMI COVID-19 MENGGUNAKAN LEARNING CURVE MODELS
}

\author{
ADAPTATION AND PRODUCTION PLANNING OF PERSONAL PROTECTIVE EQUIPMENTS DURING \\ THE COVID 19 PANDEMIC USING LEARNING CURVE MODELS
}

\author{
Nuris Maulina Ulfah ${ }^{*}$ dan Eko Ruddy Cahyadi*)1 \\ *) Departemen Manajemen, Fakultas Ekonomi dan Manajemen, IPB University \\ Jl. Agatis, Kampus IPB Darmaga, Bogor 16680, Indonesia
}

\begin{abstract}
The demand for hazmat suits and masks is increasing due to the Covid-19 Pandemic. To meet the demand, the Government is encouraging SMEs engaged in convection to produce hazmat suits and masks. The purpose of this study is to analyze the adaptation process and the application of aggregate planning as well as provide recommendations for strategies that can be applied based on the production of hazmat suits and masks from February to May 2020 at CV Bangkit Jaya as a convection UKM. The data used in this study were obtained from companies through interviews, company data, and literature studies. Processing and data analysis using learning curves and trialand-error methods of aggregate planning. The results of this study are the percentage level of the learning curve in adapting to the production of hazmat suits of 96.07 percent and masks of 99.17 percent. Then, Chase Strategy is a scenario with a minimum total cost of Rp 98834 200. Then, the strategy to control the number of workers was most appropriate for CV Bangkit Jaya in producing hazmat suits and masks.
\end{abstract}

Keywords: adaptation, hazmat suits, masks, production planning strategy, SMEs

\begin{abstract}
Abstrak: Permintaan baju hazmat dan masker semakin meningkat dikarenakan Pandemi Covid-19. Untuk memenuhi permintaan, Pemerintah mendorong UKM yang bergerak di bidang konveksi untuk memproduksi baju hazmat dan masker. Tujuan dari penelitian ini adalah menganalisis proses adaptasi dan penerapan perencanaan agregat juga memberikan rekomendasi strategi yang dapat diterapkan berdasarkan produksi baju hazmat dan masker sejak Februari hingga Mei 2020 di CV Bangkit Jaya sebagai UKM konveksi. Data yang digunakan dalam penelitian ini didapatkan dari perusahaan melalui wawancara, data perusahaan, dan studi literatur. Pengolahan dan analisis data menggunakan learning curve dan metode trial-and-error perencanaan agregat. Hasil dari penelitian ini adalah tingkat persentase kurva pembelajaran dalam beradaptasi pada produksi baju hazmat sebesar 96,07 persen dan masker sebesar 99,17 persen. Chase Strategy merupakan skenario dengan total biaya minimun yang berjumlah Rp98.834 200. Lalu, strategi pengendalian jumlah tenaga kerja paling tepat diterapkan bagi $\mathrm{CV}$ Bangkit Jaya dalam memproduksi baju hazmat dan masker.
\end{abstract}

Kata kunci: adaptasi, baju hazmat, masker, strategi perencanaan produksi, UKM

\footnotetext{
${ }^{1}$ Alamat korespondensi:

Email: ekocahyadi@apps.ipb.ac.id
} 


\section{PENDAHULUAN}

WHO menyatakan bahwa Corona Virus Disease 2019 (Covid-19) sebagai pandemi pada tanggal 11 Maret 2020 dikarenakan terjadi epidemi di berbagai negara termasuk Indonesia. Pandemi sendiri merupakan wabah penyakit global dimana organisme jenis baru muncul kemudian menginfeksi manusia dan menyebar secara berkelanjutan dikarenakan tidak ada atau sedikitnya kekebalan terhadap organisme jenis baru (CDC, 2020). Coronavirus Disease 2019 (Covid19) merupakan patogen jenis baru yang menargetkan sistem pernafasan manusia yang ditemukan pada akhir Desember 2019 di Wuhan, Provinsi Hubei, Tiongkok (Rothan et al. 2020). Untuk mencegah perluasan infeksi, Pemerintah memberlakukan Pembatasan Sosial Berskala Besar (PSBB) berdasarkan Peraturan Menteri Kesehatan Nomor 9 Tahun 2020. Menurut Jamison et al. (2017) pandemi berdampak terhadap beberapa aspek diantaranya adalah perekonomian. Menurut McKibbin dan Fernando (2020), berbagai negara akan mengalami kerugian terhadap Produk Dosmetik Bruto (PDB) dikarenakan perekonomian terkena dampak akibat wabah Covid-19 yang melanda dunia. Pernyataan ini berdasarkan analisa dengan model ekonomi yang disimulasikan dengan mengimplementasikan tujuh skenario untuk mengetahui persentase proyeksi kerugian PDB menggunakan persentase deviasi berdasarkan baseline. Berdasarkan analisa yang dilakukan, Indonesia merupakan salah satu negara yang kemungkinan akan mengalami kerugian akibat wabah Covid-19 ini.

Menurut BPS (2020), Indonesia mengalami kerugian PDB sebesar 2,41 persen pada Triwulan I-2020 dengan persentase laju pertumbuhan sebesar 2,97 persen. Kerugian ini disebabkan terjadinya kontraksi di lapangan usaha. Lapangan usaha di Indonesia didominasi oleh Usaha Kecil dan Menengah (UKM) dimana jumlah unit UKM mencapai 99,9 persen dari total jumlah usaha yang ada di Indonesia. Lalu, ada sekitar 37.000 UKM memberikan laporan mengenai dampak yang dialami selama masa Pandemi Covid-19, yaitu 56 persen mengalami penurunan penjualan, 22 persen mengalami permasalahan pada aspek biaya, 15 persen mengalami permasalahan pada pendistribusian barang, dan 4 persen mengalami permasalahan dalam mendapatkan bahan baku (Thaha, 2020).
Di Indonesia sendiri, Usaha Mikro, Kecil, dan Menengah terklasifikasi sebagai berikut berdasarkan aset, omzet, dan jumlah tenaga kerja. Jumlah aset dan omzet dari setiap skala usaha diatur dalam UU No 20 Tahun 2008 serta jumlah tenaga kerja tertera dalam data BPS pada tahun 2019. Skala usaha mikro memiliki aset dan omzet dengan urutan berjumlah 50 juta dan 300 juta serta jumlah tenaga kerja 1 sampai 4 orang. Lalu, skala usaha kecil memiliki aset dan omzet dengan urutan berjumlah diatas 50 juta sampai 500 juta dan diatas 300 juta sampai 2,5 milyar serta jumlah tenaga kerja 5 sampai 19 orang. Kemudian, skala usaha menengah memiliki aset dan omzet dengan urutan berjumlah diatas 500 juta sampai 10 milyar dan diatas 2,5 milyar sampai 50 milyar serta jumlah tenaga kerja 20 sampai 99 orang.

Selain pemberlakuan PSBB untuk mencegah perluasan infeksi, Pemerintah mewajibkan masyarakat untuk menggunakan masker setiap beraktivitas di luar rumah terlepas individu tersebut terinfeksi atau tidak. Hal ini dikarenakan Covid-19 tidak menunjukkan gejala bagi beberapa individu yang terinfeksi (WHO, 2020). Lalu, masker juga digunakan sebagai salah satu atribut Alat Pelindung Diri (APD) tenaga medis dalam menangani pasien terinfeksi Covid-19. Beberapa atribut APD yang digunakan tenaga medis seperti masker dan baju hazmat digunakan sekali untuk mencegah perluasan infeksi. Oleh karena itu, negara-negara yang menghadapi wabah Covid-19 disarankan meningkatkan produksi masker setidaknya 40 persen agar kebutuhan domestik terpenuhi (Feng et al. 2020).

Peningkatan produksi baju hazmat dan masker tidak dapat digantungkan hanya kepada industri alat kesehatan yang sudah memproduksi kedua produk sebelumnya. Oleh karena itu pemerintah mendorong UKM yang bergerak di bidang konveksi untuk ikut berkontribusi dalam memproduksi baju hazmat dan masker (Kemenkop dan UKM, 2020). Dorongan Pemerintah ini bertujuan agar kebutuhan masker bagi masyarakat tidak mengganggu pasokan masker sebagai salah satu atribut APD yang digunakan tenaga medis. Pedoman dalam memproduksi masker dan baju hazmat sesuai dengan protokol kesehatan dalam mencegah perluasan infeksi Covid-19 dipublikasikan Gugus Tugas Covid-19. Pedoman ini membantu bagi UKM dalam memproduksi baju hazmat dan masker secara mandiri. 
Ketidakpastian kapan berakhirnya pandemi Covid-19 di Indonesia maupun global mendorong semua pihak untuk menyiapkan perencanaan sebagai antisipasi dari risiko yang mungkin muncul. Lalu, pasokan baju hazmat dan masker bagi tenaga medis juga masyarakat umum harus tersedia sepanjang masa pandemi Covid-19 untuk mencegah penularan infeksi. Dengan situasi tersebut, CV Bangkit Jaya sebagai salah satu UKM yang bergerak di bidang konveksi beralih memproduksi baju hazmat dan masker untuk bertahan. Sebelum masa pandemi Covid-19, CV Bangkit Jaya belum pernah memproduksi baju hazmat dan masker maka ada proses pembelajaran yang dilalui selama kegiatan produksi. Permintaan produksi baju hazmat dan masker yang diterima berasal dari berbagai instansi seperti Pemerintah Daerah, perusahaan swasta, maupun individu. Permintaan produksi baju hazmat dan masker ini bertujuan untuk donasi bagi tenaga medis dan masyarakat agar mencegah perluasan infeksi.

Dari pemaparan permasalahan dapat dirumuskan yang bertujuan antara lain (1) Menganalisis tingkat persentase serta grafik learning curve CV Bangkit Jaya dalam memproduksi baju hazmat dan masker pertama kali untuk mengetahui kemampuan dalam menyelesaikan per unit produk selama masa pandemi Covid-19 sejak Februari hingga Mei 2020, (2) Menganalisis penerapan alternatif strategi perencanaan agregat untuk membandingkan perkiraan biaya yang dikeluarkan pada produksi baju hazmat dan masker di CV Bangkit Jaya selama masa pandemi Covid-19 sejak Februari hingga Mei 2020, dan (3) Memberikan rekomendasi strategi operasional yang dapat dilakukan CV Bangkit Jaya selama masa pandemi Covid-19 dalam memproduksi baju hazmat dan masker berdasarkan analisis learning curve dan penerapan alternatif strategi perencanaan agregat.

Selama proses adaptasi dalam memproduksi baju hazmat dan masker, permintaan baju hazmat dan masker mengalami peningkatan seiring dengan meningkatnya jumlah kasus terkonfirmasi positif Covid-19. Jumlah produksi yang dilakukan pun meningkat namun akan mendorong pekerja menemukan cara yang lebih efektif dan efisien dalam penyelesaian. Hal ini dikareanakan pekerjaan yang dilakukan secara berulang akan menuntut waktu yang lebih sedikit untuk menyelesaikan pekerjaan tersebut karena sudah terbiasa dengan kegiatan operasi dan alat yang digunakan (Anzanello dan Fogliatto, 2011).
Langkah penyelesaian dari permalasahan ini berdasarkan dari penelitian yang serupa yaitu pemenuhan jumlah produksi di suatu organisasi/ perusahaan. Penelitian terdahulu berfokus terhadap pemenuhan jumlah produksi dalam kondisi tertentu serta bagaimana suatu usaha beradaptasi terhadap perubahan. Hal yang membedakan penelitian ini dibandingkan penelitian sebelumnya yaitu proses adaptasi yang dilakukan perusahaan dalam memproduksi komoditi produk yang sebelumnya tidak pernah diproduksi.

\section{METODE PENELITIAN}

Kegiatan penelitian dilakukan di CV Bangkit Jaya yang berlokasi di Komplek Sindangsari Blok A No 1 RT 04/ RW 03 Desa Sindangpanon, Kecamatan Banjaran, Kabupaten Bandung, Jawa Barat 40377. Waktu penelitian dilakukan sejak bulan Juni hingga Juli 2020. Lalu, jenis dan sumber data yang digunakan adalah data primer yang diperoleh melalui wawancara pemilik CV Bangkit Jaya serta data sekunder yang diperoleh dari data permintaan dan produksi dan studi literatur.

Pendekatan penelitian yang digunakan adalah kuantitatif dan kualitatif. Hal ini didasarkan dari kebutuhan penelitian ini dimana instrumen yang digunakan telah ditentukan terlebih dahulu sebelum penelitian digunakan. Selain itu, pendekatan kualitatif pada penelitian ini melihat bagaimana fenomena yang terjadi di masyarakat (Mulyadi, 2011). Berdasarkan pendekatan kualitatif, penelitian ini melihat bagaimana Pandemi Covid-19 ini mempengaruhi produksi dari CV Bangkit Jaya. Sebelum masa Pandemi Covid-19, CV Bangkit Jaya belum pernah produksi baju hazmat dan masker kemudian memproduksi baju hazmat dan masker di masa Pandemi Covid-19 ini. Namun, instrumen analisis yang akan digunakan telah ditentukan karena permasalahan yang dihadapi cenderung sempit yaitu hanya di CV Bangkit Jaya yang memproduksi baju hazmat dan masker selama masa Pandemi Covid19 dengan kurun waktu dari bulan Februari hingga Mei 2021.

Metode penentuan sampel yang digunakan dalam penelitian ini adalah sensus (Supranto, 2000). Data yang digunakan berdasarkan kegiatan produksi dan operasi pembuatan baju hazmat dan masker di CV Bangkit Jaya sepanjang situasi Pandemi Covid-19 di Indonesia sejak Februari hingga Mei 2020. Lalu, CV Bangkit Jaya merupakan UKM yang bergerak di bidang 
konveksi serta memproduksi baju hazmat dan masker pertama kali di masa pandemi Covid-19 dari Februari hingga Mei 2020.

Perbedaan penelitian ini dibandingkan penelitian sebelumnya ialah penelitian ini berfokus pada perubahan produksi CV Bangkit Jaya ketika masa Pandemi Covid-19 terjadi. CV Bangkit Jaya belum pernah memproduksi baju hazmat dan masker sebelum masa Pandemi Covid-19. Sejak masa Pandemi Covid19, CV Bangkit Jaya mulai menerima permintaan untuk memproduksi baju hazmat dan masker. Analisis yang dilakukan adalah bagaimana CV Bangkit Jaya dapat beradaptasi dengan memproduksi baju hazmat dan masker selama masa Pandemi Covid-19 ditambah perencanaan produksi yang sesuai bagi kedua produk tersebut.
Alur pemikiran dari penelitian ini (Gambar 1) bahwasanya Pandemi Covid-19 terjadi di dunia kemudian berdampak terhadap perekonomian Indonesia. Situasi ini membuat jumlah kebutuhan baju hazmat dan masker meningkat sehingga UKM yang bergerak di bidang konveksi ikut berkontribusi dalam memproduksi baju hazmat dan masker untuk memenuhi kebutuhan yang meningkat. Lalu, CV Bangkit Jaya sebagai salah satu UKM yang bergerak di bidang konveksi ikut serta dalam memproduksi baju hazmat dan masker berdasarkan permintaan yang diterima. Namun, sebelum pandemi ini terjadi, CV Bangkit Jaya belum pernah memproduksi baju hazmat dan masker maka dari itu analisis adaptasi serta simulasi perencanaan agregat dilakukan. Kemudian, hasil analisis yang dilakukan dapat menentukan strategi operasional yang dapat dilakukan CV Bangkit Jaya dalam memenuhi permintaan yang diterima $\mathrm{CV}$ Bangkit Jaya.

Pandemi covid-19 menyebabkan laju pertumbuhan ekonomi Indonesia Triwulan I-2020 mengalami kerugian sebesar 2,41 persen karena terjadi lonjakan di dunia usaha

Dunia usaha terutama UKM berkontribusi besar terhadap PDB pada tahun 2018 sebesar 60 persen serta jumlah UKM mencapai 99,9 persen dari total usaha di Indonesia

Peningkatan jumlah kasus terinfeksi covid-19 juga menyebabkan kebutuhan hazmat dan masker bagi tenaga medis dan masyarakat meningkat sehingga menjadi peluang bisnis

UKM dibidang konveksi mengambil peluang bisnis dengan ikut memproduksi baju hazmat dan masker di masa pandemic agar kebutuhan baju hazmat dan masker dapat terpenuhi

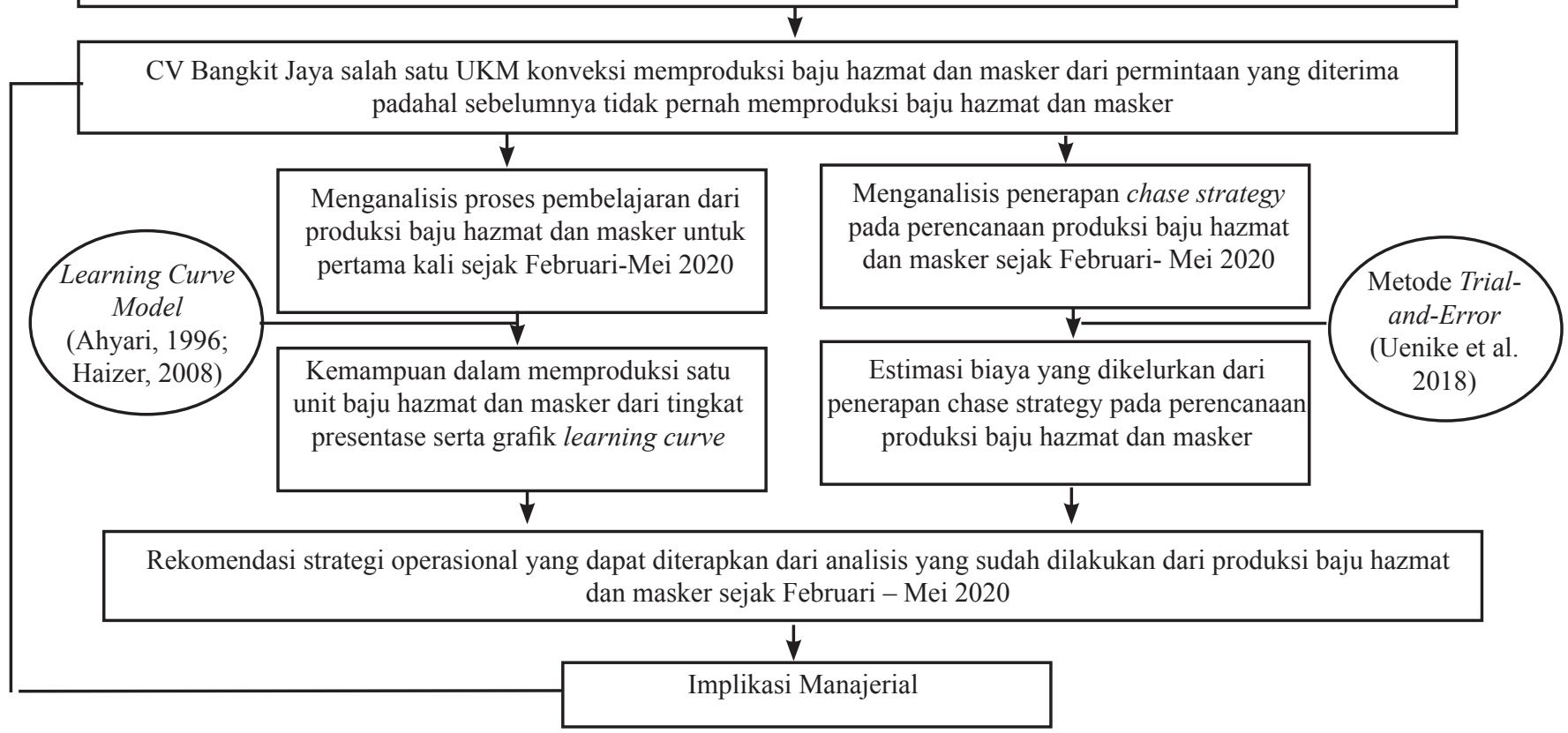

Gambar 1. Kerangka pemikiran penelitian 


\section{Learning Curve Models}

Hubungan matematis dari learning curve ini berfungsi untuk mengetahui berapa banyak jumlah unit yang telah diproduksi dan berapa lama waktu yang dibutuhkan untuk memproduksi jumlah unit tersebut. Berdasarkan prinsip learning curve dengan pendekatan logaritmik dapat dinyatakan sebagai berikut (Heizer, 2008):

$$
\mathrm{T}_{\mathrm{N}}=\mathrm{T}_{1}\left(\mathrm{~N}^{\mathrm{b}}\right)
$$

Keterangan: $\mathrm{T}_{\mathrm{N}}$ (waktu untuk produksi unit ke-N); $\mathrm{T}_{1}$ (waktu produksi unit pertama); $\mathrm{N}$ (jumlah unit produksi); b (kemiringan atau exponent slope).

Ukuran yang digunakan dalam model learning curve sebagai variabel dependen antara lain: (1) waktu untuk menghasilkan satu unit, (2) jumlah unit yang diproduksi dalam satu periode waktu, (3) biaya yang dikeluarkan dalam menghasilkan satu unit, dan (4) persentase dari unit yang tidak sesuai (Anzanello dan Fogliatto 2011). Lalu, model learning curve ini dapat diterapkan di berbagai sektor baik manufaktur maupun jasa (Grosse et al. 2015).

Perhitungan total jam tenaga kerja langsung untuk penyelesaian keseluruhan unit dapat dinyatakan sebagai berikut (Ahyari, 1996):

$$
\begin{aligned}
& \mathrm{T}_{\mathrm{N}}=\mathrm{T}_{1}\left(\mathrm{~N}^{\mathrm{b}}\right)(\mathrm{N}) \\
& \mathrm{b}=(\log (\% \text { learning curve })-2) / \log 2
\end{aligned}
$$

Tahapan dalam melakukan analisis learning curve untuk produksi baju hazmat dan masker selama masa Pandemi Covid-19 sebagai berikut: 1) Menghitung jumlah unit baju hazmat dan masker yang telah diproduksi serta lama waktu penyelesaian yang dibutuhkan untuk menyelesaikan satu unit baju hazmat dan masker di setiap periode; 2) Mengetahui waktu penyelesaian yang dibutuhkan untuk produksi satu unit baju hazmat dan masker saat pertama kali produksi; 3) Mengetahui total jam tenaga kerja yang dibutuhkan untuk seluruh unit baju hazmat dan masker yang telah diproduksi (Total Jam Kerja Seluruh Unit $=\mathrm{T}_{1}+[(\mathrm{N}-1)$ $\left.\mathrm{x} \mathrm{T}_{2}\right]$ )(Persamaan 4); 4) Mengetahui exponent slope serta tingkat persentase menggunakan persamaan (2) dan (3) dengan bantuan sifat logaritma; 5) Menghitung waktu penyelesaian yang dibutuhkan seluruh unit dengan persamaan (1) kemudian menggambarkan grafik learning curve.

\section{Metode Trial-and-Error Perencanaan Agregat}

Perencanaan jangka menengah dengan rentang waktu dari 3 hingga 18 bulan yang menentukan tingkat produksi, tenaga kerja, dan persediaan yang optimal untuk setiap bagian perencanaan yang menggunakan sumber daya dengan batasan tertentu (Jamalnia dan Feili, 2011). Dalam pembuatan perencanaan agregat dapat menggunakan strategi berikut antara lain (Eunike et al. 2018):

1. Chase Strategy merupakan strategi yang bertujuan menghasilkan tingkat persediaan yang nihil (zero inventory). Jumlah unit yang diproduksi disesuaikan dengan permintaan yang diterima perusahaan. Maka, jumlah tenaga kerja pun disesuaikan dengan permintaan yang diterima yaitu jika permintaan mengalami peningkatan maka jumlah tenaga kerja bertambah begitu pun sebaliknya.

2. Level Workforce Strategy merupakan strategi yang memiliki tingkat produksi yang sama atau jumlah pekerja yang sama sepanjang periode. Pada strategi ini, persediaan dan backorder digunakan sebagai fokus strategi operasional dimana persediaan diciptakan ketika permintaan rendah untuk pemenuhan permintaan tinggi.

3. Mixed Strategy merupakan gabungan dari dua strategi sebelumnya dimana adanya persediaan dan backorder seperti level workforce strategy serta perubahan tingkat produksi seperti chase strategy.

Tahapan dalam metode heuristik perencanaan agregat sebagai berikut (Amri et al. 2012): 1) Menentukan permintaan pada setiap periode; 2) Menentukan berapa kapasitas pada waktu regular, waktu overtime, dan waktu kebijakan subkontrak pada setiap periode; 3) Menentukan biaya upah tenaga kerja, biaya perekrutan tenaga kerja, biaya pemberhentian tenaga kerja, serta biaya penambahan persediaan; 4) Mempertimbangkan kebijakan perusahaan yang dapat diterapkan pada tenaga kerja dan tingkat persediaan; 5) Mengembangkan alternative strategi yang memungkinkan dan mengamati biaya total dari setiap alternative strategi yang memungkinkan.

Berikut perhitungan yang dapat digunakan untuk membuat perencanaan agregat dengan metode heuristik (Eunike et al. 2018):

Pekerja dibutuhkan $=$ (Kebutuhan jam kerja per bulan)/(Jam kerja per pekerja per bulan) 
Lht $=$ pekerja dibutuhkan - pekerja tersedia

Biaya perekrutan $=\mathrm{Lht} x$ biaya rekrut per pekerja

$\mathrm{Lft}=$ pekerja tersedia - pekerja dibutuhkan

Biaya pemberhentian $=$ Lft $\mathrm{x}$ biaya pemberhentian per pekerja

$\mathrm{Ct}=\mathrm{Lt} \mathrm{x}$ jam kerja per pekerja per bulan

Biaya pekerja $=\mathrm{Ct}$ x biaya per jam produksi

$\mathrm{Pt}=\min \{\mathrm{Dt}, \mathrm{Ct}\}$

$\mathrm{It}=\max \{(\mathrm{It}-1+\mathrm{Pt})-(\mathrm{Dt}+\mathrm{Bt}-1)\}$

$\mathrm{Bt}=\max \{(\mathrm{Dt}+\mathrm{Bt}-1)-(\mathrm{It}-1+\mathrm{Pt})\}$

Pekerja digunakan $=$ Total kebutuhan jam kerja per bulan / Total jam kerja pekerja per bulan

Berdasarkan pemaparan sebelumnya, CV Bangkit Jaya merupakan UKM konveksi dengan ukuran skala usaha kecil dimana produksi yang dilakukan berdasarkan permintaan yang diterima baik spesifikasi produk serta volume produk yang harus diproduksi. Sistem produksi dari CV Bangkit Jaya ini cenderung konstan dan jarang menghasilkan output yang melebihi permintaan. Maka dari itu, CV Bangkit Jaya mampu memenuhi permintaan selama pengendalian input produksi seperti jumlah tenaga kerja dapat dikendalikan.

\section{HASIL}

\section{Gambaran Umum Perusahaan}

CV Bangkit Jaya berdiri sejak tahun 1995 dan telah memproduksi kaus, kemeja, jaket, rompi, kerudung, dan lain-lain selama produks dapat diproduksi oleh industri konveksi. Rata-rata kapasitas produksi CV Bangkit Jaya dalam sebulan untuk kemeja dapat mencapai 5.000 unit, jaket dapat mencapai 2.000 unit, dan kaus dapat mencapai antara 50.000 hingga 100.000 unit. Lalu, rata-rata pendapatan kotor dalam sebulan mencapai 250 juta rupiah dengan rata-rata pendapatan bersih mencapai 25 juta rupiah.
Selama masa Pandemi Covid-19, CV Bangkit Jaya mengalami penurunan produksi sebesar 50 persen. Hal ini mendorong CV Bangkit Jaya melakukan peralihan produksi dengan memproduksi baju hazmat dan masker dikarenakan permintaan kedua produk tersebut meningkat. Selain itu, adanya dorongan Pemerintah untuk KUMKM yang bergerak di bidang fashion dan konveksi untuk memproduksi baju hazmat dan masker untuk digunakan masyarakat umum dan tenaga medis.

\section{Data Produksi Baju Hazmat dan Masker}

Sejak Februari 2020, CV Bangkit Jaya mulai memproduksi masker dengan volume permintaan sejumlah 10.000 unit kemudian mengalami penurunan di bulan selanjutnya yaitu 5.000 unit. Kemudian, pada bulan Mei 2020, volume permintaan masker mengalami peningkatan sejumlah 15.000 unit. Lalu, produksi baju hazmat dimulai pada bulan April dengan volume permintaan yaitu 1.000 unit dan mengalami peningkatan di bulan selanjutnya yaitu 10.000 unit. Data tertera pada Tabel 1.

Jam kerja CV Bangkit Jaya selama masa Pandemi Covid-19 adalah 9 jam kerja dengan 6 hari kerja yang diasumsikan dalam sebulan membutuhkan 26 hari kerja. Namun, beberapa pekerjaan dapat dibawa ke rumah masing-masing. Jumlah tenaga kerja tetap yang dipekerjakan berjumlah 10 orang dan jumlah tenaga kerja yang paling banyak yang pernah dipekerjakan berjumlah 50 orang. Upah yang diberikan untuk tenaga kerja bersifat borongan dengan rata-rata upah yang diberikan yaitu $\mathrm{Rp} 800.000,00$ dengan upah per jam kerja berkisar Rp7.500,00. Jika CV Bangkit Jaya mengalami lonjakan permintaan maka perekrutan tenaga kerja. Namun, perekrutan tenaga kerja di CV Bangkit Jaya tidak mengeluarkan biaya dikarenakan pekerjaan tidak membutuhkan keterampilan khusus maka asumsi biaya yang dikelurkan berkisar Rp200,00 per orang. Lalu, biaya pemberhentian tenaga yang dikeluarkan berkisar Rp78.000,00. Kemudian, produksi baju hazmat dan masker melebihi volume permintaan yang diterima dan produksi yang berlebih dijadikan persediaan untuk memenuhi permintaan selanjutnya. Jumlah persediaan baju hazmat yaitu 30 unit dengan biaya yang dikenakan Rp1.500.000,00 dan jumlah persediaan masker yaitu 2.000 unit dengan biaya yang dikenakan Rp4.000.000,00. Ringkasan data pada Tabel 2. 
Tabel 1. Data permintaan dan produksi baju hazmat dan masker

\begin{tabular}{lcccccc}
\hline \multirow{3}{*}{ Bulan } & \multicolumn{3}{c}{ Masker } & \multicolumn{3}{c}{ Baju Hazmat } \\
\cline { 2 - 7 } & Permintaan & Produksi & Waktu & Permintaan & Produksi & Waktu \\
\cline { 2 - 7 } & (unit) & (unit) & (hari) & (unit) & (unit) & (hari) \\
\hline Februari & 10.000 & 10.000 & 12 & 0 & 0 & 0 \\
Maret & 5.000 & 5.000 & 6 & 0 & 0 & 0 \\
April & 0 & 0 & 0 & 1.000 & 1.000 & 12 \\
Mei & 15.000 & 17.000 & 18 & 10.000 & 10.030 & 26 \\
Total & 30.000 & 32.000 & 36 & 11.000 & 11.030 & 38 \\
\hline
\end{tabular}

Tabel 2. Data-data mengenai biaya, jumlah tenaga kerja, serta waktu kerja

\begin{tabular}{lc}
\hline Biaya & Jumlah \\
\hline Biaya Jam Kerja Reguler (Clt) & Rp7.500,00 per jam \\
Biaya Perekrutan Tenaga Kerja (Clht) & Rp200,00 per orang \\
Biaya Pemberhentian Tenaga Kerja (Clft) & Rp78.000,00 per orang \\
Biaya Persediaan (Clt) & Rp112,00 per jam kerja per bulan \\
Biaya Backorder (Cbt) & - \\
Jumlah Pekerja Awal (L0) & 10 orang \\
Jumlah Pekerja Maksimum & 50 orang \\
Jumlah Hari Kerja Per Bulan & 26 hari \\
Jumlah Jam Kerja Per Hari & 9 jam \\
\hline
\end{tabular}

\section{Analisis Learning Curve Produksi Baju Hazmat}

Sejak produksi baju hazmat di bulan April 2020, CV Bangkit Jaya telah memproduksi 11.030 unit baju hazmat dengan lama waktu penyelesaian yang dibutuhkan satu unit baju hazmat yaitu 1,08 jam pada bulan April 2020. Lalu, pada bulan Mei 2020, lama waktu penyelesaian satu unit baju hazmat yaitu 0,63 jam. Ringkasan data tertera pada Tabel 3.

Berdasarkan data tersebut, total jam tenaga kerja yang dibutuhkan setelah memproduksi baju hazmat sejumlah 11.030 unit baju hazmat dapat dihitung menggunakan persamaan (4) sebagai berikut:

Total Jam Kerja 11.030 unit $=1,08$ jam $+(11.029$ unit x 0,63 jam)

Berdasarkan perhitungan diatas menggunakan persamaan (4) bahwa total jam kerja yang dibutuhkan dalam menyelesaikan 11.030 unit baju hazmat berkisar 6.948,36 jam kerja. Total jam tenaga kerja dari 11.030 unit baju hazmat diasumsikan dengan $\mathrm{T}_{11.030}$. Untuk menentukan tingkat persentase produksi baju hazmat dari bulan April hingga Mei 2020, exponent slope perlu diketahui sebelumnya. Exponent slope dapat ditemukan melalui perhitungan menggunakan persamaan (2) dengan bantuan sifat logaritmik. Berikut perhitungan yang dilakukan untuk produksi 11.030 unit baju hazmat berdasarkan persamaan (2) menggunakan sifat logaritmik:

$$
\begin{gathered}
\mathrm{T}_{\mathrm{N}}=\mathrm{T}_{1}\left(\mathrm{~N}^{\mathrm{b}}\right)(\mathrm{N}) \\
\mathrm{T}_{11.030}=\mathrm{T}_{1}\left(11.030^{\mathrm{b}}\right)(11.030) \\
6.948,36=1,08\left(11.030^{\mathrm{b}}\right)(11.030)
\end{gathered}
$$

$\log 6.948,36=\log 1,08+b(\log 11.030)+\log 11.030$

$$
\begin{gathered}
3,84=0,03+b(4,04)+4,04 \\
b=(3,84-0,03-4,04) / 4,04 \\
b=-0,058
\end{gathered}
$$

Berdasarkan perhitungan yang dilakukan, exponent slope bernilai $-0,058$ memiliki interpretasi bahwa akan selalu negatif dengan asumsi total jam kerja akan menurun dengan meningkatnya volume produksi. Lalu, nilai b dimasukkan ke dalam persamaan (3) untuk menentukan tingkat persentase learning curve produksi baju hazmat sejak bulan April hingga Mei 2020. Perhitungan berdasarkan persamaan (3) menggunakan sifat logaritmik sebagai berikut:

$$
\begin{gathered}
\mathrm{b}=(\log (\% \text { learning curve })-2) / \log 2 \\
-0,058=(\log (\% \text { learning curve })-2) / 0,3 \\
\log (\% \text { learning curve })=(-0,058 \times 0,3)+2 \\
\log (\% \text { learning curve })=1,983 \\
\% \text { learning curve }=10^{1,983} \\
\text { \% learning curve }=96,07
\end{gathered}
$$


Tabel 3. Data produksi baju hazmat serta lama waktu penyelesaian per unit

\begin{tabular}{lccccc}
\hline \multirow{2}{*}{ Bulan } & Produksi & Waktu & Jumlah Tenaga Kerja & Per Tenaga Kerja & Waktu Per Unit \\
\cline { 2 - 6 } & (unit) & (hari) & (orang) & (unit/ orang) & (jam) \\
\hline Februari & 0 & 0 & 0 & 0 & 0 \\
Maret & 0 & 0 & 0 & 0 & 0 \\
April & 1.000 & 12 & 10 & 100 & 1,08 \\
Mei & 10.030 & 26 & 27 & 371,48 & 0,63 \\
Total & 11.030 & 38 & 37 & 471 & 1,71 \\
\hline
\end{tabular}

Selanjutnya, grafik learning curve produksi baju hazmat didapat melalui perhitungan menggunakan persamaan (1) dimana exponent slope diperlukan juga. Berikut perhitungan yang dilakukan untuk menggambarkan grafik learning curve produksi baju hazmat sejak bulan April hingga Mei 2020:

$$
\mathrm{T}_{\mathrm{N}}=\mathrm{T}_{1}\left(\mathrm{~N}^{\mathrm{b}}\right)(\mathrm{N})
$$

Perhitungan untuk unit ke-1 sebagai berikut:

$\mathrm{T}_{1}=1,08\left(1^{-0,058}\right)$

$\mathrm{T}_{1}=1,08$

Perhitungan untuk unit ke-2 sebagai berikut:

$\mathrm{T}_{2}=1,08\left(2^{-0,058}\right)$

$\mathrm{T}_{2}=1,038$

Berdasarkan perhitungan yang telah dilakukan, grafik learning curve dari produksi baju hazmat sejak bulan April hingga Mei 2020 (Gambar 2) memiliki tingkat persentase sebesar 96,07 persen dengan exponent slope bernilai negatif yang menandakan hubungan negatif antara total jam kerja untuk produksi baju hazmat dengan volume produksi. Dimana total jam kerja akan mengalami penurunan sebesar 3,93 persen seiring peningkatan volume produksi dari permintaan yang diterima dengan kelipatan lima ribu.

Berdasarkan grafik learning curve produksi masker, adanya penurunan waktu yang diperlukan dalam menyelesaikan satu unit baju hazmat. Proses pembelajaran dalam memproduksi 11.030 unit baju hazmat paling signifikan ketika jumlah produksi masih kurang dari 310 unit setelah memproduksi lebih dari 310 unit proses pembelajaran cenderung konstan. Artinya, CV Bangkit Jaya membutuhkan hingga 310 unit untuk beradaptasi dalam memproduksi baju hazmat. Lalu, grafik learning curve dalam memproduksi baju hazmat akan cenderung konstan setelah produksi berada diatas 310 unit.

\section{Analisis learning curve produksi baju masker}

Sejak produksi masker di bulan Februari 2020, CV Bangkit Jaya telah memproduksi 32.000 unit masker dengan lama waktu penyelesaian yang dibutuhkan satu unit masker yaitu 0,108 jam pada bulan Februari dan Maret 2020. Lalu, pada bulan Mei 2020, lama waktu penyelesaian satu unit masker yaitu 0,095 jam. Ringkasan data tertera pada Tabel 4. Berdasarkan data tersebut, total jam tenaga kerja yang dibutuhkan setelah memproduksi masker sejumlah 32.000 unit baju hazmat dapat dihitung menggunakan persamaan (4) sebagai berikut:

Total Jam Kerja 32.000 unit $=0,108$ jam + (31.999 unit x 0,095 jam)

Berdasarkan perhitungan menggunakan persamaan (4) bahwa total jam kerja yang dibutuhkan dalam menyelesaikan 32.000 unit masker berkisar 3.049,42 jam kerja. Total jam tenaga kerja dari 32.000 unit masker diasumsikan dengan $\mathrm{T}_{32.000}$. Untuk menentukan tingkat persentase produksi masker dari bulan Februari hingga Mei 2020, exponent slope perlu diketahui sebelumnya. Exponent slope dapat ditemukan melalui perhitungan menggunakan persamaan (2) dengan bantuan sifat logaritmik. Berikut perhitungan yang dilakukan untuk produksi 32.000 unit masker berdasarkan persamaan (2) menggunakan sifat logaritmik:

$$
\begin{gathered}
\mathrm{T}_{\mathrm{N}}=\mathrm{T}_{1}\left(\mathrm{~N}^{\mathrm{b}}\right)(\mathrm{N}) \\
\mathrm{T}_{32.000}=\mathrm{T}_{1}\left(32.000^{\mathrm{b}}\right)(32.000) \\
3.049,42=0,108\left(32.000^{\mathrm{b}}\right)(32.000)
\end{gathered}
$$

$\log 3.049,42=\log 0,108+b(\log 32.000)+\log 32.000$

$$
\begin{gathered}
3,84=-0,967+b(5)+5 \\
b=(3,84-(-0,967)-5) / 5 \\
b=-0,012
\end{gathered}
$$

Berdasarkan perhitungan yang dilakukan, exponent slope bernilai $-0,012$ memiliki interpretasi bahwa akan selalu negatif dengan asumsi total jam kerja akan menurun dengan meningkatnya volume produksi. 
Lalu, nilai b dimasukkan ke dalam persamaan (3) untuk menentukan tingkat persentase learning curve produksi masker sejak bulan April hingga Mei 2020. Perhitungan berdasarkan persamaan (3) menggunakan sifat logaritmik sebagai berikut:

$$
\begin{gathered}
\mathrm{b}=(\log (\% \text { learning curve })-2) / \log 2 \\
-0,012=(\log (\% \text { learning curve })-2) / 0,3 \\
\log (\% \text { learning curve })=(-0,012 \times 0,3)+2 \\
\log (\% \text { learning curve })=1,996 \\
\% \text { learning curve }=10^{1,996} \\
\% \text { learning curve }=99,17
\end{gathered}
$$

Selanjutnya, grafik learning curve produksi masker didapat melalui perhitungan menggunakan persamaan (1) dimana exponent slope diperlukan juga. Berikut perhitungan yang dilakukan untuk menggambarkan grafik learning curve produksi masker sejak bulan Februari hingga Mei 2020:

$$
\mathrm{T}_{\mathrm{N}}=\mathrm{T}_{1}\left(\mathrm{~N}^{\mathrm{b}}\right)(\mathrm{N})
$$

Perhitungan untuk unit ke-1 sebagai berikut:

$\mathrm{T}_{1}=1,08\left(1^{-0,012}\right)$

$\mathrm{T}_{1}=1,08$

Perhitungan untuk unit ke-2 sebagai berikut:

$\mathrm{T}_{2}=1,08\left(2^{-0,012}\right)$

$\mathrm{T}_{2}=1,07$

Berdasarkan perhitungan yang telah dilakukan, grafik learning curve dari produksi masker sejak bulan Februari hingga Mei 2020 memiliki tingkat persentase sebesar 99,17 persen dengan exponent slope bernilai negatif yang menandakan hubungan negatif antara total jam kerja untuk produksi masker dengan volume produksi. Dimana total jam kerja akan mengalami penurunan sebesar 0,83 persen seiring peningkatan volume produksi dari permintaan yang diterima dengan kelipatan sepuluh.

Tabel 4. Data produksi masker serta lama waktu penyelesaian per unit

\begin{tabular}{lccccc}
\hline \multirow{2}{*}{ Bulan } & Produksi & Waktu & Jumlah Tenaga Kerja & Per Tenaga Kerja & Waktu Per Unit \\
\cline { 2 - 6 } & (unit) & (hari) & (orang) & (unit/ orang) & (jam) \\
\hline Februari & 10.000 & 12 & 10 & 1.000 & 0,108 \\
Maret & 5.000 & 6 & 10 & 500 & 0,108 \\
April & 0 & 0 & 0 & 0 & 0 \\
Mei & 17.000 & 18 & 10 & 1.700 & 0,095 \\
Total & 32.000 & 36 & 30 & 3.200 & 0,311 \\
\hline
\end{tabular}

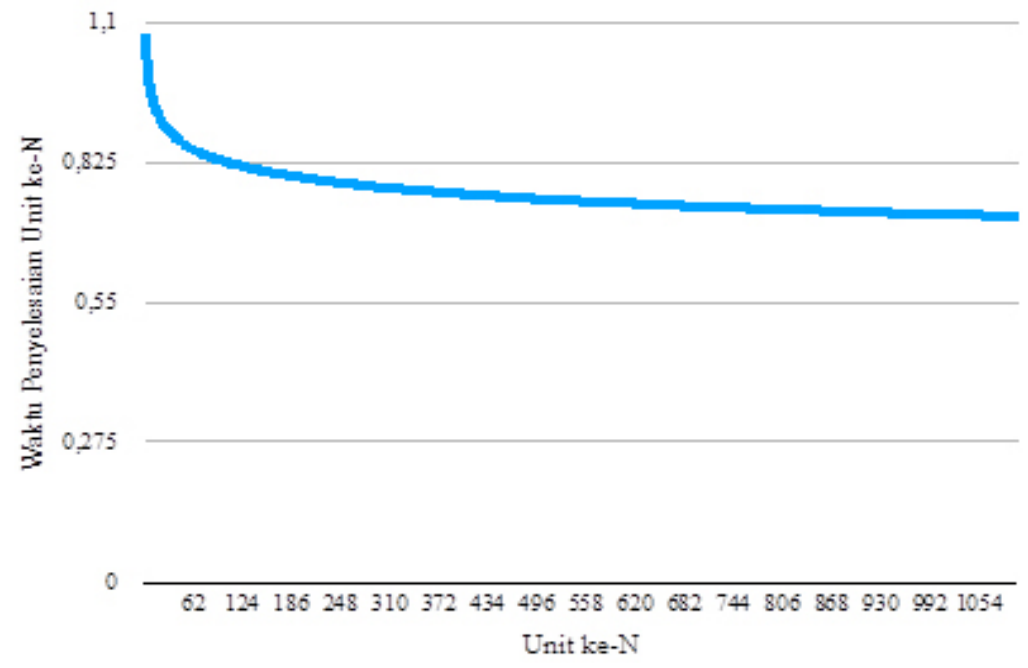

Gambar 2. Grafik learning curve produksi baju hazmat 
Berdasarkan grafik learning curve produksi masker, adanya penurunan waktu yang diperlukan dalam menyelesaikan satu unit masker. Proses pembelajaran dalam memproduksi 32.000 unit masker paling signifikan ketika jumlah produksi masih kurang dari 1.302 unit setelah memproduksi lebih dari 1.302 unit proses pembelajaran cenderung konstan. Artinya, CV Bangkit Jaya membutuhkan hingga 1.302 unit untuk beradaptasi dalam memproduksi masker. Lalu, grafik learning curve dalam memproduksi masker akan cenderung konstan setelah produksi berada diatas 1.302 unit.

\section{Analisis Simulasi Perencanaan Agregat Baju Hazmat dan Masker}

Alternatif strategi atau skenario yang diterapkan dalam analisis simulasi ini yaitu (1) Chase strategy dimana kapasitas produksi disesuaikan dengan volume permintaan di setiap periode dimana jumlah tenaga kerja yang mengikuti volume permintaan untuk kapasitas produksi, (2) Level workforce strategy dimana tingkat produksi dan jumlah tenaga kerja tetap namun persediaan digunakan untuk memenuhi lonjakan permintaan, dan (3) Mixed strategy dimana adanya persediaan seperti level workforce strategy namun tingkat produksi yang berubah dimana jumlah tenaga kerja menyesuaikan dengan volume permintaan yang diterima perusahaan.

Perhitungan menggunakan rata-rata jam kerja standar per unit dari produksi baju hazmat dan masker. Ratarata jam kerja standar per unit untuk produksi baju hazmat yaitu 0,855 jam sementara rata-rata jam kerja standar per unit untuk produksi masker yaitu 0,104 jam. Ringkasan data tertera pada Tabel 5.

Berdasarkan rata-rata jam kerja standar per unit, total jam kerja untuk produksi baju hazmat dan masker sejak Februari hingga Mei 2020 didapatkan. Total jam kerja didapat dari perkalian antara volume permintaan dengan rata-rata jam kerja stanadar per unit. Ringkasan data pada Tabel 6 .

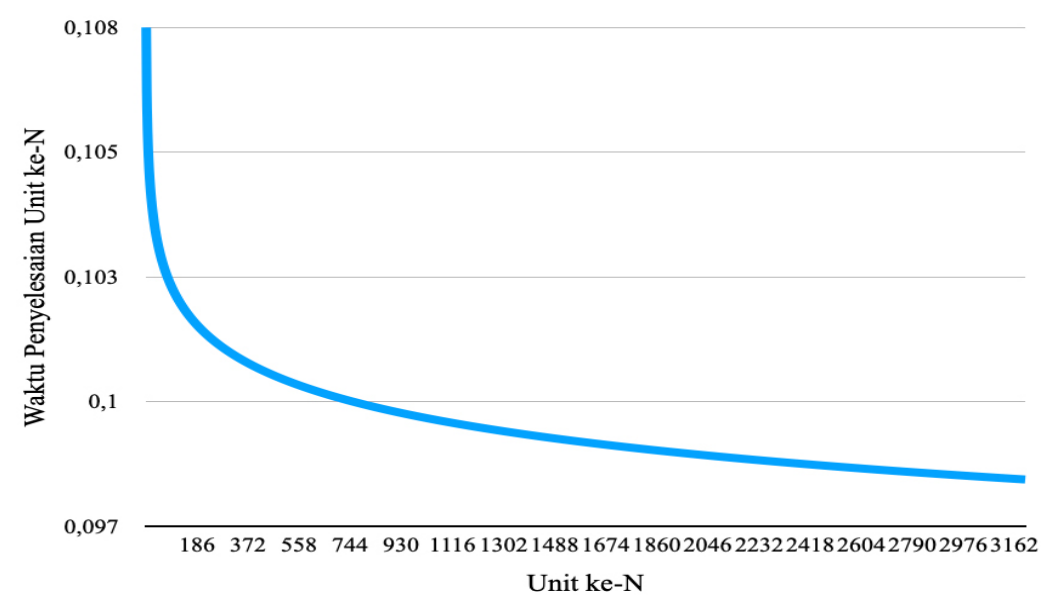

Gambar 3. Grafik learning curve produksi masker

Tabel 5. Rata-rata jam kerja standar per unit

\begin{tabular}{lc}
\hline Produk & Rata-Rata Jam Kerja Standar Per Unit \\
\hline Baju Hazmat & 0,855 \\
Masker & 0,104 \\
Total & 32.000 \\
\hline
\end{tabular}

Tabel 6. Jumlah jam kerja dari setiap periode permintaan

\begin{tabular}{lccc}
\hline \multirow{2}{*}{ Bulan } & \multicolumn{2}{c}{ Produk } & \multirow{2}{*}{ Agregat } \\
\cline { 2 - 3 } & Baju Hazmat & Masker & \\
\hline Februari & 0 & $1.037,65$ & 1.040 \\
Maret & 0 & 518,82 & 520 \\
April & 854,96 & 0 & 860 \\
Mei & $8.549,55$ & $1.556,47$ & 10.110 \\
\hline
\end{tabular}


Penerapan skenario Chase Strategy pada perencanaan produksi baju hazmat dan masker sejak Februari hingga Mei 2020, fokus dari skenario ini adalah strategi pengendalian jumlah tenaga kerja dimana tingkat produksi disesuaikan dengan volume permintaan. Pengendalian jumlah tenaga kerja dapat melalui perekrutan dan pemberhentian tenaga kerja. Perekrutan tenaga kerja dilakukan apabila terjadi peningkatan volume permintaan dengan biaya perekrutan tenaga kerja yang dikeluarkan senilai Rp200,00 per orang sementara pemberhentian dilakukan apabila terjadi penurunan volume permintaan dengan biaya pemberhentian yang dikeluarkan senilai Rp78.000,00 per orang. Ringkasan data tertera pada Tabel 7.

Penerapan skenario Level Workforce Strategy pada perencanaan produksi baju hazmat dan masker sejak Februari hingga Mei 2020, fokus dari skenario ini adalah strategi pengendalian jumlah persediaan dimana tingkat produksi dan jumlah tenaga kerja tetap disesuaikan namun persediaan timbul apabila permintaan kurang dari tingkat produksi yang kemudian disimpan untuk memenuhi permintaan selanjutnya. Strategi pengendalian jumlah persediaan menimbulkan biaya persediaan ketika menyimpan produksi yang berlebih. Biaya persediaan yang dikeluarkan bernilai Rp112,00 per unit per jam kerja per bulan. Ringkasan data tertera pada Tabel 8.

Penerapan skenario Mixed Strategy pada perencanaan produksi baju hazmat dan masker sejak Februari hingga Mei 2020 merupakan kombinasi dari skenario Chase Strategy dan Level Workforce Strategy. Fokus dari skenario ini adalah jumlah tenaga kerja yang bervariasi mengikuti volume permintaan yang diterima. Namun, tingkat persediaan diadakan dikarenakan jumlah produksi tidak menyesuaikan dengan volume permintaan yang diterima melainkan kapasitas dari setiap tenaga kerja yang ada di CV Bangkit Jaya. Biaya perekrutan tenaga kerja yang dikeluarkan bernilai Rp200,00 per orang dan biaya pemberhentian tenaga kerja yang dikeluarkan senilai Rp78.000,00 per orang. Lalu, biaya persediaan yang dikeluarkan senilai Rp112,00 per unit per jam kerja per bulan. Ringkasan data tertera pada Tabel 9 .

Tabel 7. Penerapan chase strategy pada produksi baju hazmat dan masker

\begin{tabular}{lccccc}
\hline Periode ke- & 1 & 2 & 3 & 4 & Total \\
\hline Hari & 26 & 26 & 26 & 26 & 104 \\
Jam kerja/Pekerja/Bulan & 234 & 234 & 234 & 234 & 936 \\
Permintaan & 1.040 & 520 & 860 & 10.110 & 12.530 \\
Pekerja Dibutuhkan & 5 & 3 & 4 & 44 & 14 \\
Pekerja Tersedia & 10 & 5 & 3 & 4 & 44 \\
Pekerja Digunakan & 5 & 3 & 4 & 44 & 14 \\
Biaya Pekerja & 8.775 .000 & 5.265 .000 & 7.020 .000 & 77.220 .000 & 98.280 .000 \\
Rekrut Pekerja & 0 & 0 & 1 & 40 & 0 \\
Biaya Perekrutan & 0 & 0 & 200 & 8.000 & 0 \\
Pekerja Diberhentikan & 5 & 2 & 0 & 0 & 30 \\
Biaya Pemberhentian & 390.000 & 156.000 & 0 & 0 & 546.000 \\
Kapasitas & 1.170 & 702 & 936 & 10.296 & 13.104 \\
Unit Diproduksi & 1.040 & 520 & 860 & 10.110 & 12.530 \\
Persediaan & 0 & 0 & 0 & 0 & 0 \\
Biaya Persediaan & 0 & 0 & 0 & 0 & 0 \\
Backorder & 9.165 .000 & 5.421 .000 & 7.020 .200 & 77.228 .000 & 98.834 .200 \\
Biaya Backorder & & & & 0 \\
Total Biaya & 0 & 0 & 0 & 0 \\
\hline
\end{tabular}


Tabel 8. Penerapan level workforce strategy pada produksi baju hazmat dan masker

\begin{tabular}{lccccc}
\hline Periode ke- & 1 & 2 & 3 & 4 & Total \\
\hline Hari & 26 & 26 & 26 & 26 & 104 \\
Jam kerja/Pekerja/Bulan & 234 & 234 & 234 & 234 & 936 \\
Permintaan & 1.040 & 520 & 860 & 10.110 & 12.530 \\
Pekerja Dibutuhkan & 5 & 3 & 4 & 44 & 56 \\
Pekerja Tersedia & 10 & 14 & 14 & 14 & 52 \\
Pekerja Digunakan & 14 & 14 & 14 & 14 & 56 \\
Biaya Pekerja & 24.570 .000 & 24.570 .000 & 24.570 .000 & 24.570 .000 & 98.280 .000 \\
Rekrut Pekerja & 4 & 0 & 0 & 0 & 4 \\
Biaya Perekrutan & 800 & 0 & 0 & 0 & 800 \\
Pekerja Diberhentikan & 0 & 0 & 0 & 0 & 0 \\
Biaya Pemberhentian & 0 & 0 & 0 & 0 & 0 \\
Kapasitas & 3.276 & 3.276 & 3.276 & 3.276 & 13.104 \\
Unit Diproduksi & 3.276 & 3.276 & 3.276 & 3.276 & 13.104 \\
Persediaan & 2.236 & 4.992 & 7.408 & 574 & 15.210 \\
Biaya Persediaan & 249.314 & 556.608 & 825.992 & 64.001 & 1.695 .915 \\
Backorder & 0 & 0 & 0 & 0 & 0 \\
Biaya Backorder & 0 & 0 & 0 & 0 & 0 \\
Total Biaya & 24.820 .114 & 25.126 .608 & 25.395 .992 & 24.634 .001 & 99.976 .715 \\
\hline
\end{tabular}

Tabel 9. Penerapan mixed strategy pada produksi baju hazmat dan masker

\begin{tabular}{lccccc}
\hline Periode ke- & 1 & 2 & 3 & 4 & Total \\
\hline Hari & 26 & 26 & 26 & 26 & 104 \\
Jam kerja/org/bln & 234 & 234 & 234 & 234 & 936 \\
Permintaan & 1.040 & 520 & 860 & 10.110 & 12.530 \\
Kapasitas & 2.340 & 2.340 & 2.340 & 6.318 & 13.338 \\
Pekerja Dibutuhkan & 5 & 3 & 4 & 44 & 56 \\
Pekerja Digunakan & 10 & 10 & 10 & 27 & 57 \\
PekerjaTersedia & 10 & 10 & 10 & 10 & 40 \\
Rekrut Pekerja & 0 & 0 & 0 & 17 & 17 \\
Biaya Perekrutan & 0 & 0 & 0 & 3.400 & 3.400 \\
Pekerja Diberhentikan & 0 & 0 & 0 & 0 & 0 \\
Biaya Pemberhentian & 0 & 0 & 0 & 0 & 0 \\
Pekerja Digunakan & 10 & 10 & 10 & 27 & 57 \\
Biaya Pekerja & 17.550 .000 & 17.550 .000 & 17.550 .000 & 47.385 .000 & 100.035 .000 \\
Unit Diproduksi & 2.340 & 2.340 & 2.340 & 6.318 & 13.338 \\
Persediaan & 1.300 & 3.120 & 4.600 & 808 & 9.828 \\
Biaya Persediaan & 144.950 & 347.880 & 512.900 & 90.092 & 1.095 .822 \\
Backorder & 0 & 0 & 0 & 0 & 0 \\
Biaya Backorder & 0 & 0 & 0 & 0 & 0 \\
Total Biaya & 17.694 .950 & 17.897 .880 & 18.062 .900 & 47.478 .492 & 101.134 .222 \\
\hline
\end{tabular}


Berdasarkan penerapan skenario Chase Strategy, Level Workforce Strategy, dan Mixed Strategy, ada biaya yang dikeluarkan dari setiap penerapan skenario dalam perencanaan produksi. Biaya yang dikeluarkan antara lain biaya perekrutan dan pemberhentian tenaga kerja, biaya pekerja, biaya persediaan, dan biaya backorder. Selain itu, jumlah tenaga kerja dari setiap penerapan skenario terhadap perencanaan produksi didapat. Perbandingan dari penerapan Chase Strategy, Level Workforce Strategy, dan Mixed Strategy terhadap perencanaan produksi baju hazmat dan masker sejak Februari hingga Mei 2020 pada Tabel 10.

\section{Implikasi Manajerial}

Berdasarkan analisis yang telah dilakukan, CV Bangkit Jaya dapat menerapkan strategi pengendalian jumlah tenaga kerja atau Chase Strategy pada perencanaan produksi baju hazmat dan masker selama pandemi Covid-19. Namun, kendala dari CV Bangkit Jaya adalah penetapan biaya terkait tenaga kerja antara biaya pekerja atau upah yang diterima, biaya perekrutan, dan biaya pemberhentian. Penetapan biaya yang diperlukan antara lain standar pemberian upah apakah berdasarkan jam kerja atau per unit barang yang dihasilkan. Setelah penetapan biaya yang terkait tenaga kerja, perencanaan produksi menggunakan strategi pengendalian tenaga kerja atau Chase Strategy dapat dilakukan berdasarkan permintaan yang diterima atau permintaan sebelumnya. Perencanaan produksi ini membantu dalam menentukan jumlah pekerja yang akan direkrut dan diberhentikan. Lalu, jumlah pekerja ini akan menentukan perkiraan total biaya yang akan dikeluarkan perusahaan selama periode produksi tersebut. Selanjutnya, perekrutan dan pemberhentian dilakukan dengan berpedoman pada perencanaan yang sudah dilakukan dari permintaan yang diterima atau produksi sebelumnya. Perekrutan dan pemberhentian ini juga harus memperhatikan biaya yang akan dikeluarkan. Hal ini dikarenakan biaya dari strategi pengendalian jumlah tenaga kerja atau Chase Strategy sangat bergantung dengan jumlah pekerja dibandingkan strategi lainnya. Terakhir, evaluasi di akhir periode dalam memproduksi baju hazmat dan masker bertujuan untuk membandingkan total biaya perencanaan produksi dengan total biaya produksi aktual.

\section{KESIMPULAN DAN SARAN}

\section{Kesimpulan}

Penelitian ini tidak mengalami pertentangan dengan konsep dasar maupun hipotesis permasalahan yang telah dirumuskan. Lalu, berdasarkan hasil dan pembahasandapat disimpulkan bahwa tingkat persentase learning curve CV Bangkit Jaya yang beradaptasi dalam memproduksi baju hazmat dan masker yaitu masingmasing persentase 96,07 persen dan 99,17 persen. Lalu, proses adaptasi yang signifikan terjadi sebelum produksi 310 unit tercapai untuk baju hazmat dan sebelum produksi 1.302 unit tercapai untuk masker.

Selanjutnya, Chase Strategy merupakan strategi dengan total biaya terkecil dibandingkan Level Workforce Strategy dan Mixed Strategy. Total biaya dari Chase Strategy berjumlah Rp98.834.200,00 dengan jumlah tenaga kerja akhir berjumlah 44 orang. Kemudian, berdasarkan analisis yang dilakukan, strategi yang dapat diterapkan CV Bangkit Jaya dalam perencanaan produksi baju hazmat dan masker yaitu strategi pengendalian jumlah tenaga kerja atau Chase Strategy. Hasil penelitian ini dapat dijadikan pedoman bagi CV Bangkit Jaya dalam memproduksi baju hazmat dan masker di masa Pandemi Covid-19. Lalu, hasil penelitian ini juga dapat dijadikan pedoman apabila kejadian serupa terjadi.

Tabel 10. Perbandingan hasil simulasi chase strategy, level workforce strategy, dan mixed strategy terhadap produksi baju hazmat dan masker

\begin{tabular}{lccc}
\hline & Chase Strategy & Level Workforce Strategy & Mixed Strategy \\
\hline Biaya Perekrutan & 8.200 & 800 & 3.400 \\
Biaya Pemberhentian & 546.000 & 0 & 0 \\
Biaya Pekerja & 98.280 .000 & 98.280 .000 & 100.035 .000 \\
Biaya Persediaan & 0 & 1695.915 & 1.095 .822 \\
Biaya Backorder & 0 & 0 & 0 \\
Total Biaya & 9834200 & 99976715 & 101134222 \\
Jumlah Tenaga Kerja & 44 & 14 & 27 \\
\hline
\end{tabular}




\section{Saran}

Berdasarkan penelitian yang dilakukan, saran yang dapat diajukan oleh penulis adalah sebagai berikut: bagi perusahaan, pengendalian jumlah tenaga kerja tetap dilakukan namun biaya yang dikeluarkan untuk tenaga kerja harus diperhatikan dan direncanakan lebih matang. Hal ini bertujuan agar perusahaan tidak mengalami kerugian. Bagi penelitian selanjutnya, proyeksi permintaan dapat ditambahkan agar meramalkan permintaan di masa mendapat kemudian dianalisis menggunakan perencanaan agregat untuk prakiraan perencanaan produksi selanjutnya.

\section{DAFTAR PUSTAKA}

Ahyari A. 1996. Perencanaan Proses Produksi Jilid 1. Yogyakarta: BPFPE.

Amri A, Trisna T, Harahap EN. 2012. Perencanaan pengendalian produksi air minum dalam kemasan menggunakan metode aggregate planning. Malikussaleh Industrial Engineering Journal 1(1): 11-18.

Anzanello MJ, Fogliatto FS. 2011. Learning curve models and applications: Literature review and research directions. International Journal of Industrial Ergonomics 41(5): 573 - 583.

[BPS] Badan Pusat Statistik. 2019. Subjek Industri Mikro dan Kecil. https://www.bps.go.id/ subject/170/industri-mikro-dan-kecil. html\#subjekViewTab6. [6 Jul 2020].

[BPS] Badan Pusat Statistik. 2020. Ekonomi Indonesia Triwulan I 2020 Tumbuh 2,97 Persen. https:// www.bps.go.id/pressrelease/2020/05/05/1736/ ekonomi-indonesia-triwulan-i-2020-tumbuh-297-persen.html. [16 Jul 2020].

Centers for Disease Control and Prevention. 2020. Coronavirus Disease 2019 Situation Summary. https://www.cdc.gov/coronavirus/2019-ncov/ cases-updates/summary.html. [13 Mei 2020].

Eunike A et al. 2018. Perencanaan Produksi dan Pengendalian Persediaan. Malang: Univesitas Brawijaya Press.

Feng S, Shen C, Xia N, Song W, Fan M, Cowling BJ. 2020. Rational use of face masks in the Covid19 Pandemic. The Lancet Respiratory Medicine 8(5): 434-436. https://doi.org/10.1016/S22132600(20)30134-X.
Grosse EH, Glock CH, Müller S. 2015. Production economics and the learning curve: a metaanalysis. International Journal of Production Economics 170: 401 - 412. doi:10.1016/j. ijpe.2015.06.021.

Heizer J. 2008. Companion Website for Operations Management and Student CD and Student DVD Package, $9^{\text {th }}$ Edition. https://wps.prenhall.com/ wps/media/objects/2234/2288589/ModE.pdf. [9 Juni 2020].

Jamalnia A, Feili A. 2013. Asimulation testing and analysis of aggregate production planning strategies. Production Planning \& Control 24(6): 423-448.

Jamison DT, Gelband H, Horton S, Jha P, Laxminarayan R, Mock CN, Nugent R. 2018. Disease Control Priorities: Improving Health and Reducing Poverty, $3^{\text {rd }}$ edition. Washington:The World Bank.

Juliantara IK, Mandala K. 2020. Perencanaan dan pengendalian produksi agregat pada usaha tedung UD Dwi Putri di Klungkung. E-Jurnal Manajemen 9(1): 99 - 118. doi: 10.24843/ EJMUNUD.2020.v09.i01.p06.

Kementerian Koperasi dan Usaha Kecil dan Menengah. 2020. Kemkop dan UKM ajak KUMKM Indonesia Produksi Masker Kain. http://www. depkop.go.id/read/kemkop-dan-ukm-ajakkumkm-indonesia-produksi-masker-kain. $\quad$ [10 Mei 2020].

Kementerian Koperasi dan Usaha Kecil dan Menengah. 2020. Menkop dan UKM: APD Produksi UMKM Binaan Telah Terkurasi Sesuai Standar Kesehatan. http://www.depkop.go.id/read/ menkop-dan-ukm-apd-produksi-umkm-binaantelah-terkurasi- sesuai-standar-kesehatan. [22 Jun 2020].

McKibbin W, Fernando R. 2020. The Global Macroeconomic Impacts of Covid-19: Seven Scenarios. SSRN Electronic Journal, Working Paper 19: 1-42.

Mulyadi M. 2011. Penelitian kuantitatif dan kualitatif serta pemikiran dasar menggabungkannya. Jurnal Studi Komunikasi dan Media 15 (1): 127 -138 .

Musaji S, Schulze WS, De Castro JO. 2019. Howlong does it take to "get to" the learning curve? Academy of Management Journal 1 - 44. 
Octavianti IA, Setyanto NW, Tantrika CFM. 2013. Perencanaan produksi agregat produk tembakau rajang P01 dan P02 di PT X. Jurnal Rekayasa dan Manajemen Sistem Industri 1(2): 264 274.

Ramadhani A, Rahman A, Tantrika CFM. 2014. Perencanaan agregat chase strategy dengan analisis kebutuhan operator dan sesuai fluktuasi permintaan rokok (studi kasus: PR. Adi Bungsu Malang). Jurnal Rekayasa dan Manajemen Sistem Industri 2(6): 1192 - 1202.

Reicita FA. 2019. Analisis perencanaan produksi pada PT. armstrong industri indonesia dengan metode forecasting dan agregat planning. Jurnal Ilmiah Teknik Industri 7(3): 160 - 168. doi: DOI: 10.24912/jitiuntar.v7i3.6340.

Rothan HA, Byrareddy SN. 2020. The epidemiology and pathogenesis of coronavirus disease (COVID19) Outbreak. Journal of Autoimunity 109:1-4. https://doi.org/10.1016/j.jaut.2020.102433.
Supranto J. 2000. Statistik Teori dan Aplikasi Edisi Keenam Jilid 1. Jakarta: Penerbit Erlangga.

Thaha AF. 2020. Dampak Covid-19 terhadap UMKM di Indonesia. Jurnal Brand 2(1): 147-153.

Thompson P. 2012. The relationship between unit cost and cumulative quantity and the evidence for organizational learning-by-doing. Journal of Economic Perspective 26 (3): 203 - 224.

Wardhani AR. 2010. Perencanaan agregat dengan metode transportasi pada PT. X Pasuruan. Widya Teknika 18 (1): 6 - 10. doi: 10.31328/jwt. v18i1.65.

World Health Organization. 2020. Advice on the Use of Masks in the Context of Covid-19. https://apps. who.int/iris/bitstream/handle/10665/332293/ WHO-2019-nCov-IPC_Masks-2020.4-eng. pdf? sequence $=1 \&$ isAllowed $=y$. [16 Jun 2020]. 